\title{
Hypothalamic involvement in chronic migraine
}

M F P Peres, M Sanchez del Rio, M L V Seabra, S Tufik, J Abucham, J Cipolla-Neto, S D Silberstein, E Zukerman

\begin{abstract}
Objectives-Chronic migraine (CM), previously called transformed migraine, is a frequent headache disorder that affects $2 \%-3 \%$ of the general population. Analgesic overuse, insomnia, depression, and anxiety are disorders that are often comorbid with CM. Hypothalamic dysfunction has been implicated in its pathogenesis, but it has never been studied in patients with $\mathrm{CM}$. The aim was to analyze hypothalamic involvement in $\mathbf{C M}$ by measurement of melatonin, prolactin, growth hormone, and cortisol nocturnal secretion.
\end{abstract}

Methods-A total of 338 blood samples (13/patient) from 17 patients with $C M$ and nine age and sex matched healthy volunteers were taken. Melatonin, prolactin, growth hormone, and cortisol concentrations were determined every hour for 12 hours. The presence of comorbid disorders was also evaluated.

Results-An abnormal pattern of hypothalamic hormonal secretion was found in CM. This included: (1) a decreased nocturnal prolactin peak, (2) increased cortisol concentrations, (3) a delayed noc-

Sao Paulo Headach Center, R Maestro Cardim, 887 01323-001, Sao Paulo SP, Brazil M F P Peres

Jefferson Headache Center, Thomas Jefferson University

Hospital, Philadelphia PA, USA

M Sanchez del Rio

$S$ D Silberstein

Federal University of Sao Paulo, Brazil

M F P Peres

M L V Seabra

$S$ Tufik

J Abucham

Universidade de Sao Paulo-Instituto des Ciencias Biomedicas J Cipolla-Neto

Hospital Israelita Albert Einstein

E Zukerman

Correspondence to: Dr M F P Peres, Sao Paulo Headache Center, R Maestro Cardim, 887 01323-001, Sao Paulo SP, Brazil

marioperes@yahoo.com

Received 29 December 2000 and in revised form

1 May 2001

Accepted 20 July 2001 turnal melatonin peak in patients with CM, and (4) lower melatonin concentrations in patients with $\mathbf{C M}$ with insomnia. Growth hormone secretion did not differ from controls.

Conclusion-These results support hypothalamic involvement in $\mathrm{CM}$, shown by a chronobiologic dysregulation, and a possible hyperdopaminergic state in patients with $\mathrm{CM}$. Insomnia might be an important variable in the study findings. (F Neurol Neurosurg Psychiatry 2001;71:747-751)

Keywords: chronic migraine; prolactin; cortisol; melatonin; hypothalamus

Chronic migraine (CM) is a debilitating disorder that affects $2.4 \%$ of the general population ${ }^{1}$ and accounts for most consultations in headache clinics- $40 \%{ }^{2}$ to $65 \% .^{3}$ Because CM affects people during their peak productive years, it imposes a significant decrease in their quality of life and considerable economical burden to society. ${ }^{4}$

Patients with CM often have a history of episodic migraine beginning in their teenage years. The headache frequency increases over months or years, and the associated symptoms of nausea, vomiting, photophobia, and phonophobia become less prominent. ${ }^{5}$ Chronic migraine is a complex syndrome with many associated conditions including acute medication overuse ${ }^{6}$ generalised anxiety disorder $(70 \%),{ }^{7}$ major depression $(80 \%),{ }^{7}$ and insomnia $(71 \%)$.

Little is known about the causes and mechanisms of CM. The transformation of episodic migraine to $\mathrm{CM}$ (>15 days/month) remains an enigma. Several mechanisms have been alleged to be the cause of the change in frequency and symptoms, including chronic neurogenic inflammation, central sensitisation, defective central pain modulation, hypothalamic dysfunction, or a combination of these.

Hypothalamic involvement in the pathogenesis of cluster headache is well known, ${ }^{9}$ whereas the role of the hypothalamus in the pathophysiology of chronic migraine has never been studied. For this reason we chose to explore the hypothalamic-tuberoinfundibular system (prolactin, growth hormone), the hypothalamichypophyseal-adrenal axis (cortisol), and pineal gland function (melatonin) in CM.

\section{Material and methods}

A study was performed from February to April 1999, at Sao Paulo Federal University Headache Clinic. A total of 26 subjects were enrolled in the study. All subjects provided written consent for the experimental procedure approved by the Sao Paulo federal university ethics committee. Seventeen patients, 14 women and three men, aged 31 (SD 9) met the criteria of Silberstein and Lipton ${ }^{6}$ for CM. Nine healthy volunteers, seven women and two men, aged 29 (SD 6), also participated in the study as controls.

Eleven of the patients were overusing analgesic drugs (nine were overusing dipyrone, three caffeine, two isometeptene, two acetylsalicilic acid, two acetaminophen, and two ergotamine. Four were diagnosed with fibromyalgia and eight with insomnia (table 1).

All patients with CM were instructed not to take acute medication more than 2 or 3 days a week during the week before the blood determination. None had taken any preventive medication for at least 3 months before the study. None had hypertension, alcoholism, or history of any relevant medical disease, and none smoked. Hormone concentrations were determined within 1 week after enrollment. Subjects were admitted to hospital and kept under controlled environmental luminosity conditions not exceeding 50 Lux. A venous line was placed at 1800 and blood samples were taken every hour from 1900 to 0700 . A total of 13 samples/subject were collected. Women's samples were obtained during the follicular phase of the menstrual cycle. 
Concentrations of hormones were determined in each blood sample by radioimmunoassay The intra-assay and interassay coefficients of variation (CVs ) for the assays were as follows: prolactin $4 \%$ and $7 \%$; cortisol $4 \%$ and $6 \%$; growth hormone $5 \%$ and $8 \%$; and melatonin $6 \%$ and $10 \%$ respectively. Four patients did not have growth hormone measured, two because their body mass index was greater than 30, and two because they were 21 years of age or younger (table 1 ).

Depression was assessed by the Beck depression inventory $\mathrm{II},{ }^{10}$ and anxiety by the trait and state anxiety inventory. ${ }^{11}$ The American College of Rheumatology diagnostic criteria were used for the diagnosis of fibromyalgia. ${ }^{12}$ Patients were diagnosed with insomnia according to the criteria shown:

- Difficulty of sleep onset or maintenance

- Insomnia at least three times a week for at least 1 month

- Insomnia interfering with daily personal functioning

- Patient fulfills the proposed diagnostic criteria of Silberstein and Lipton ${ }^{6}$ for CM.

ANALYSIS

The time of peak, peak concentration, area under the curve (AUC), and the average of 13 samples in patients versus controls for each hormone were analyzed. We also accounted for other variables such as depression, anxiety, analgesic overuse, insomnia, and fibromyalgia. A phase delay in the melatonin nocturnal peak was considered if the time of the peak occurred after $0300 .^{13}$

The Mann-Whitney rank sum test and student's $t$ test were used to compare the means, peak concentrations, and AUCs between subgroups (depression, anxiety, analgesic overuse, insomnia, and fibromyalgia). Fisher's exact test was used for the time of peak analysis. Analysis of variance (ANOVA) with repeated measures was used to compare

Table 1 Clinical characteristics of the patients

\begin{tabular}{lllllll}
\hline $\begin{array}{l}\text { CM } \\
\text { patient }\end{array}$ & Age & Sex & $\begin{array}{l}\text { Years of } \\
\text { CM }\end{array}$ & Fibromyalgia & Insomnia & Analgesic overuse \\
\hline 1 & 27 & F & 0.25 & & & - \\
2 & 21 & M & 0.86 & & - \\
3 & 25 & F & 2 & & + & \\
4 & 28 & F & 2 & & & Aspirin, caffeine \\
5 & 47 & F & 16 & + & & Ergotamine, dipirone \\
6 & 16 & F & 4 & & & - \\
7 & 34 & M & 20 & & + & - \\
8 & 25 & F & 3 & + & + & Dipirone \\
9 & 35 & F & 10 & & + & Dipirone, aspirin, acetaminophen \\
10 & 23 & F & 5 & & & Dipirone \\
11 & 37 & F & 6 & + & + & Dipirone, caffeine \\
12 & 28 & F & 3 & & + & Ergotamine, acetaminophen \\
13 & 38 & M & 20 & + & + & - \\
14 & 46 & F & 20 & & & Dipirone \\
15 & 26 & F & 1 & & & Dipirone, isomepthene \\
16 & 44 & F & 30 & & + & Dipirone, caffeine, aspirin \\
17 & 27 & F & 10 & & & Dipirone, isomepthene \\
Controls & & & & & - & \\
18 & 28 & F & - & - & - & - \\
19 & 31 & F & - & - & - & - \\
20 & 22 & M & - & - & - & - \\
21 & 44 & F & - & - & - & - \\
22 & 24 & F & - & - & - & - \\
23 & 29 & F & - & - & - & - \\
24 & 27 & F & - & - & - & - \\
25 & 30 & F & - & - & - & - \\
26 & 27 & M & - & - & - & - \\
\hline & & & & & &
\end{tabular}
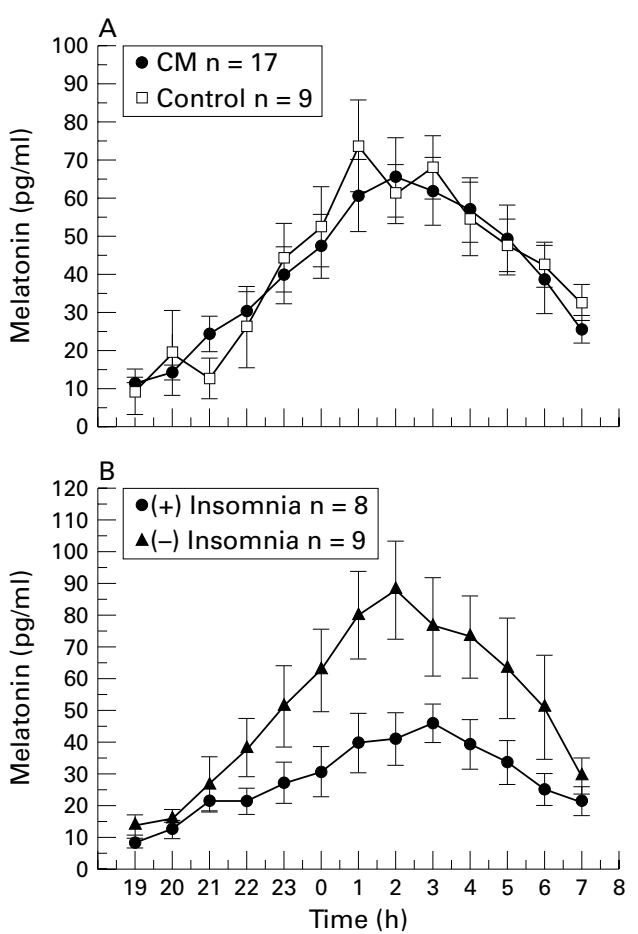

Figure 1 Melatonin nocturnal profile in patients with $C M v$ controls and patients with CM with insomnia v without insomnia.

patients and controls. Pearson's test was used for the correlation analysis. Values are expressed as means (SD). The level of significance was taken as $\mathrm{p}<0.05$.

\section{Results}

MELATONIN

Eight patients with CM (47\%) had a phase delay in the melatonin peak whereas none of the controls had $(\mathrm{p}<0.05$, fig 1$)$. There was no significant difference in nocturnal melatonin secretion between patients and controls (40.3 (19.1) v 43.2 (16.0) $\mathrm{pg} / \mathrm{ml}$, respectively).

Patients who had CM plus insomnia $(n=8)$ had melatonin concentrations (28.0 (19.9) $\mathrm{pg} / \mathrm{ml}$ ), AUC (347.5 (128.6) pg.h/ml), and peak concentration $(50.3(19.6) \mathrm{pg} / \mathrm{ml})$ that were significantly lower than those in patients with CM without insomnia (51.9 (10.3) pg/ml; 643.3 (238.0) pg.h/ml, and 111.9 (45.7) pg/ml, respectively, all $\mathrm{p}<0.05)$ and that were also significantly lower than those in controls. There was no difference in time of peak or in the prolactin, cortisol, or growth hormone concentrations and between patients with and without nocturnal melatonin phase delay.

PROLACTIN

Fifty three per cent of patients had peak concentrations of prolactin lower than 25 $\mathrm{ng} / \mathrm{ml}(18$ (3) $\mathrm{ng} / \mathrm{ml})$, but only two of the nine controls did $(15.6 \mathrm{ng} / \mathrm{ml})(\mathrm{p}<0.05$; fig 2$))$. The mean concentration of prolactin in patients with CM was not significantly different from controls (26 (11) $\mathrm{ng} / \mathrm{ml}$ v 37 (17) $\mathrm{ng} / \mathrm{ml}$ respectively, $\mathrm{p}=0.06)$. There was no significant difference in the mean prolactin peak in patients with $\mathrm{CM}$ with or without analgesic overuse (23 (8) v 31 (13) ng/ml). There was no 

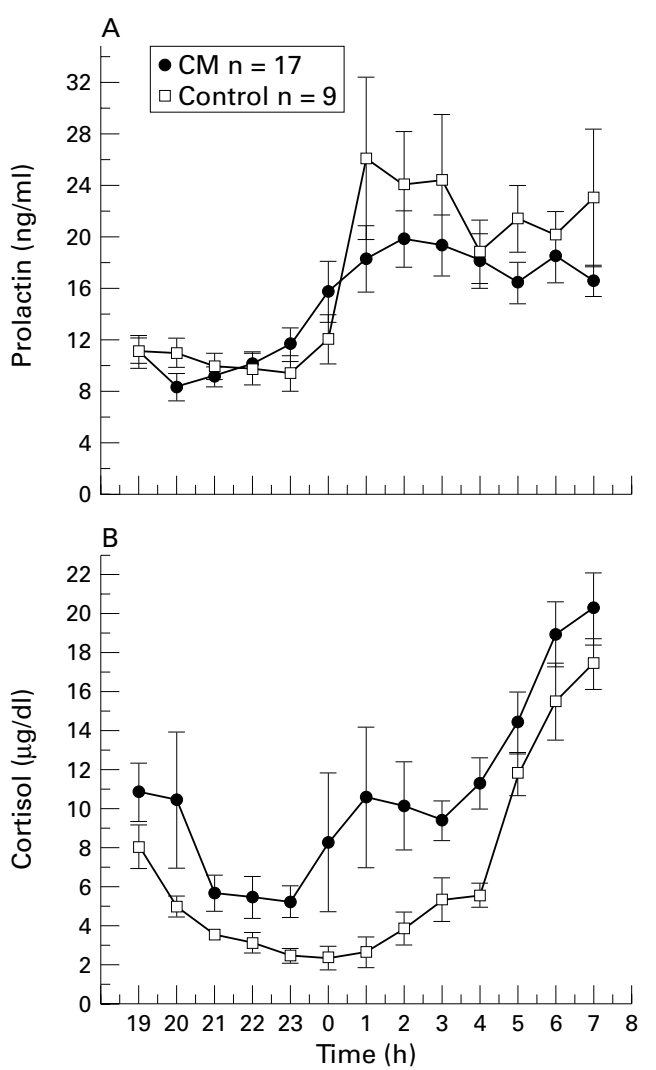

Figure 2 Prolactin and cortisol nocturnal profile in patients with CM v controls.

significant difference in the mean or AUC between patients and controls or between patients with or without analgesic overuse and with or without insomnia.

CORTISOL

Patients had higher cortisol concentrations than controls (10.3 (4.3) $v 6.7$ (1.2) $\mu \mathrm{g} / \mathrm{dl}$; higher AUC (101.7 (49.0) v 76.6 (14.3) $\mu \mathrm{g} . \mathrm{h} /$ dl); and higher peak (22.5 (14.2) v 18.6 (4.1) $\mu \mathrm{g} / \mathrm{dl})$; all $\mathrm{p}<0.05$, fig 2)). There were no significant differences between patients with or without insomnia, drug overuse, or fibromyalgia.

There was an increase in cortisol concentration between 2300 and 0100 that deviated from the expected pattern with respect to controls, although this increase did not reach significance.

GROWTH HORMONE

There was no difference between patients and controls in growth hormone secretion (mean 2.0 (1.2) v 2.9 (1.9) ng/dl, respectively). Repetitive measure analysis failed to show any significant difference. Analysis of the subgroups did not show any difference in concentrations or time of peak.

\section{Discussion}

Prolactin, growth hormone, cortisol, and melatonin concentrations were determined every hour for 12 hours to investigate the role of the hypothalamus in chronic migraine. The hormones were measured during the night as the highest concentrations are usually at this time.
We found decreased prolactin peak secretion, increased cortisol concentrations, a phase delay in the melatonin peak, and lower melatonin concentrations in patients with CM with insomnia.

MELATONIN

Lower melatonin concentrations have been reported in episodic migraine, menstrual migraine, and cluster headache. This is the first study of melatonin in patients with CM.

Forty seven per cent of patients with CM had a significant phase delay in the melatonin peak, and half had insomnia. Melatonin concentrations, peak secretion, and AUCs were significantly lower in patients with $\mathrm{CM}$ who had insomnia than in controls and patients with CM without insomnia.

Lower melatonin concentrations, but not a phase shift in the nocturnal peak, have been reported in patients with insomnia. ${ }^{14} \mathrm{~A}$ phase delay in the nocturnal melatonin peak has been reported in patients with delayed sleep phase syndrome (DSPS), ${ }^{15}$ and these patients treated with $5 \mathrm{mg}$ melatonin had a great improvement of both sleep and its associated headaches. ${ }^{16}$

The circadian rhythm of melatonin secretion is regulated by the suprachiasmatic nucleus in the hypothalamus. ${ }^{17}$ The phase delay in the melatonin peak found in patients with CM supports the theory that hypothalamic involvement in CM leads to a chronobiological dysfunction; however, it is not known whether it is a cause or a consequence of the disease. It could also be due to an underlying delayed sleep phase syndrome and other sleep disorder comorbidity.

Melatonin is a potent endogenous scavenger of reactive oxygen species acting as a neuroprotective agent in processes involving free radical formation and excitatory amino acid release. ${ }^{18}$ Evidence in laboratory animals shows that this neuroprotective action is probably mediated through inhibition of NF-kappaB, a peptide upstream of tumour necrosis factor ( $T N F \alpha)$, which is known to be involved in inflammatory processes and sensitisation ${ }^{19}$ It is hypothesised that dysfunction in melatonin secretion can favour sensitisation and persistence of inflammatory products. Melatonin receptors have also been found in cerebral arteries and in the hypothalamus. ${ }^{20}$

Melatonin may have a role in the treatment of CM, particularly in those patients with insomnia, but further studies are necessary to confirm this. Its other favourable qualities for CM treatment include its analgesic properties, ${ }^{21}$ and the fact that it potentiates a GABA inhibitory effect $\mathrm{t}^{22}$ and inhibits prostaglandin $\mathrm{E}$ synthesis. ${ }^{23}$ Melatonin is a sensitive marker of endogenous rhythms ${ }^{24}$ and is thought to play an important part in the adaptative mechanisms to changing enviromental and endogenous stimuli. ${ }^{25}$

\section{PROLACTIN}

Patients with chronic migraine show a decreased nocturnal prolactin peak. Studies have reported normal prolactin values in episodic migraine, ${ }^{26-29}$ but none of them analyzed the 
nocturnal prolactin profile. This is the first study on prolactin concentrations in CM. Based on the hypersensitivity of dopamine receptors that some migraineurs manifest, modulating dopaminergic neurotransmission has been a therapeutic target. This is demonstrated by the induction of yawning, nausea, vomiting, and hypotension by dopaminergic agonists. ${ }^{30} 31$ In addition, some migraineurs show allelic variations within the DRD2 gene that has been hypothesised to predispose to a hypersensitive state to dopamine. ${ }^{32}$ Prolactin secretion is one measure of dopaminergic function, as dopamine is its main inhibitory factor. The measurement of prolactin can indirectly provide information on the dopaminergic system in CM.

We hypothesise that there is a sustained nocturnal inhibition of prolactin by dopamine and, therefore, an indirect increase in dopamine secretion. Many antidopaminergic agents have been successfully used in acute (droperidol, ${ }^{33}{ }^{34}$ chlorpromazine, ${ }^{35}$ prochlorperazine,${ }^{36}$ metoclopramide, domperidone, ${ }^{37}$ haloperidol $\left.{ }^{38}\right)$, and preventive (flunarizine, ${ }^{39}$ olanzapine (personal communication)) headache treatment. Our findings support the use of these drugs in CM, but clinical trials are needed to confirm their efficacy.

Tumour necrosis factor- $\alpha$, a potent proinflammatory cytokine involved in pain and inflammatory disorders such as multiple sclerosis, ${ }^{40}$ psoriasis, ${ }^{41}$ meningitis, ${ }^{42}$ and migraine, ${ }^{43}$ has been shown to inhibit prolactin release. Its algesic effects are due to sensitising actions on nociceptive afferents, upregulation of other proinflammatory and algesic proteins, and a triggering of cyclooxygenase dependent pathways to synthesise prostaglandins. If we consider neurogenic inflammation as part of the pathogenesis of migraine, it is possible that the suppressed peak of prolactin could also be due to an increase in $\mathrm{TNF} \alpha$.

CORTISOL

Cortisol concentrations are raised in many conditions related to $\mathrm{CM}$, such as depression, ${ }^{44}$ anxiety, ${ }^{45}$ insomnia, ${ }^{46}$ fibromyalgia, ${ }^{47}$ and chronic pain..$^{48}$ This is the first study of cortisol concentrations in patients with CM. We found higher concentrations of cortisol, suggesting that the hypophyseal-adrenal axis is activated in patients with CM compared with controls. Glucocorticoids exert numerous effects on metabolism, inflammation, and immunity, ${ }^{49}$ and play an important part in pain inhibitory mechanisms. ${ }^{50}$

It is also important to consider the long term effect of a hypercortisol state in patients with CM. Arterial hypertension was found by Mathew $^{8}$ in the transformation of episodic to chronic daily headache. The increase in cortisol concentrations could be the biological basis for this finding, although patients with hypertension were excluded from our study. Cortisol concentrations should be studied in patients with CM and arterial hypertension in the future.
GROWTH HORMONE

Growth hormone regulation is complex; neuropeptides, neurotransmitters, and opioids are involved. Dopamine also inhibits growth hormone secretion in the hypophysis, ${ }^{51}$ and the study of this hormone is another indirect way to address the dopaminergic system. Our data did not show any significant difference in the analysis of growth hormone. However, any differences may not have been great enough to be detected with the small sample studied. The role of growth hormone in headaches remains unknown.

\section{Conclusion}

We found an abnormal pattern of hypothalamic hormonal secretion in CM. This comprised: (1) a decreased nocturnal prolactin peak, (2) increased cortisol concentrations, (3) a delayed nocturnal melatonin peak in patients with CM, and (4) lower melatonin concentrations in patients with $\mathrm{CM}$ with insomnia. Secretion of growth hormone did not differ from controls. Overall, these results support the involvement of the hypothalamus in the pathophysiology of CM as shown by a chronobiological dysregulation, and a possible hyperdopaminergic state in patients with CM.

1 Castillo J, Munoz P, Guitera V, et al. Epidemiology of chronic daily headache in the general population. Headache 1998;39:190-6.

2 Mathew NT. Transformed migraine. Cephalalgia 1993; 13(suppl 12):78-83.

3 Saper JR. Daily chronic headache. Neurol Clin 1990;8:891901.

4 Osterhaus JT, Gutterman DL, Plachetka JR. Healthcare resource and lost labour costs of migraine headache in the US. Pharmacoeconomics 1992;2:67-76.

5 Mathew NT, Stubits E, Nigam MP. Transformation of episodic migraine into daily headache: analysis of factors. Headache 1982;22:66-8.

6 Silberstein SD, Lipton RB. Chronic daily headache (in process citation). Curr Opin Neurol 2000;13:277-83.

7 Verri AP, Proietti CA, Galli C, et al. Psychiatric comorbidity in chronic daily headache. Cephalalgia 1998;18(suppl 21):45-9.

8 Mathew N. Chronic daily headache: clinical features and natural history. In: Nappi G, ed. Headache and depression: natural history. In: Nappi G, ed. Headache and depression:
serotonin pathways as a common clue. New York: Raven Press serotonin pathways as

9 Leone M, Bussone G. A review of hormonal findings in cluster headache. Evidence for hypothalamic involvement. cluster headache. Evidence fo
Cephalalgia 1993;13:309-17.

10 Beck AT, Steer RA, Ball R, et al. Comparison of Beck depression inventories -IA and -II in psychiatric outpatients. F Pers Assess 1996;67:588-97.

11 Spielberger CD. The measurement of state and trait anxiety: conceptual and methodological issues. 713-25. In: Levi L, ed. Emotions: their parameters and measurement. New York: Raven Press, 1975. (WL.102.E54.1975.)

12 Wolfe F, Smythe HA, Yunus MB, et al. The American College of Rheumatology 1990. Criteria for the classification of fibromyalgia. Report of the Multicenter Criteria of fibromyalgia. Report of the Multicenter Criteria 72.

13 Lewy AJ, Cutler NL, Sack RL. The endogenous melatonin profile as a marker for circadian phase position. $₹$ Biol profile as a marker for circ

14 Hajak G, Rodenbeck A, Staedt J, et al. Nocturnal plasma melatonin levels in patients suffering from chronic primary insomnia. F Pineal Res 1995;19:116-22.

15 Shibui K, Uchiyama M, Okawa M. Melatonin rhythms in delayed sleep phase syndrome. F Biol Rhythms 1999;14:726.

16 Nagtegaal JE, Smits MG, Swart AC, et al. Melatoninresponsive headache in delayed sleep phase syndrome: preliminary observations. Headache 1998;38:303-7.

17 Penev PD, Zee PC. Melatonin: a clinical perspective. Ann Neurol 1997;42:545-53.

18 Franceschini D, Skaper SD, Floreani $M$, et al. Further evidences for neuroprotective effects of melatonin. Adv Exp Med Biol 1999;467:207-15.

19 Lezoualc'h F, Sparapani M, Behl C. N-acetyl-serotonin (normelatonin) and melatonin protect neurons against oxidative challenges and suppress the activity of the transcription factor NF-kappaB. F Pineal Res 1998;24:168-78. 
20 Stankov B, Cozzi B, Lucini V, et al. Characterization and mapping of melatonin receptors in the brain of three mammalian species: rabbit, horse and sheep. A comparative
vitro binding study. Neuroendocrinology 1991;53:214-21.

21 Lakin ML, Miller CH, Stott ML, et al. Involvement of the pineal gland and melatonin in murine analgesia. Life $\mathrm{Sci}$ 1981;29:2543-51.

22 Rosenstein RE, Cardinali DP. Melatonin increases in vivo GABA accumulation in rat hypothalamus, cerebellum, cerebral cortex and pineal gland. Brain Res 1986;398:403-6.

23 Leach CM, Reynoldson JA, Thorburn GD. Release of E prostaglandins into the cerebrospinal fluid and its inhibition by melatonin after cervical stimulation in the rabbit. Endocrinology 1982;110:1320-4.

24 Lewy AJ, Cutler NL, Sack RL. The endogenous melatonin profile as a marker for circadian phase position. $7 \mathrm{Bio}$ Rhythms 1999;14:227-36.

25 Brzezinski A. Melatonin in humans. $N$ Engl $f$ Med 1997;336:186-95.

26 Lara Capellan JI, Varela DC, Gutierrez Garcia JM, et al. Tuberoinfundibular dopaminergic tonus in common migraine. Headache 1990;30:282-4.

27 D'Andrea G, Cananzi AR, Grigoletto F, et al. The effect of dopamine receptor agonists on prolactin secretion in childhood migraine. Headache 1988:28:354-9.

28 Epstein MT, Hockaday JM, Hockaday TD. Prolactin and migraine [letter]. Lancet 1974;ii:523.

29 Nattero G, Corno M, Savi L, et al. Prolactin and migraine: effect of L-dopa on plasma prolactin levels in migraineurs and normals. Headache 1986;26:9-12.

30 Peroutka SJ. Dopamine and migraine [see comments]. Neurology 1997;49:650-6.

31 Cerbo R, Barbanti P, Buzzi MG, et al. Dopamine hypersensitivity in migraine: role of the apomorphine test. Clin Neuropharmacol 1997;20:36-41.

32 Peroutka SJ, Wilhoit T, Jones K. Clinical susceptibility to migraine with aura is modified by dopamine D2 receptor (DRD2) NcoI alleles [see comments]. Neurology 1997;49: 201-6.

33 Wang SJ, Silberstein SD, Young WB. Droperidol treatment of status migrainosus and refractory migraine. Headache of status migrain

34 Richman PB, Reischel U, Ostrow A, et al. Droperidol for acute migraine headache. Am f Emerg Med 1999;17:398400 .

35 Da Costa AR, Monzillo PH, Sanvito WL. Use of chlorpromazine in the treatment of headache at an emergency service. Arq Neuropsiquiatr 1998;56:565-8.

36 Ginder S, Oatman B, Pollack M. A prospective study of iv magnesium and i.v. prochlorperazine in the treatment of headaches. F Emerg Med 2000;18:311-5.

37 Pfaffenrath V, Scherzer S. Analgesics and NSAIDs in the treatment of the acute migraine attack. Cephalalgia 1995;15(suppl 15):14-20.
38 Fisher $\mathrm{H}$. A new approach to emergency department therapy of migraine headache with intravenous therapy of migraine headache with intravenous

39 Lucetti C, Nuti A, Pavese N, et al. Flunarizine in migraine prophylaxis: predictive factors for a positive response. Cephalalgia 1998;18:349-52.

40 Navikas V, Link H. Review: cytokines and the pathogenesis of multiple sclerosis. F Neurosci Res 1996;45:322-33.

41 Mizutani H, Ohmoto Y, Mizutani T, et al. Role of increased production of monocytes TNF-alpha, IL-1beta and IL-6 in psoriasis: relation to focal infection, disease activity and responses to treatments. F Dermatol Sci 1997;14:145-53.

42 Glimaker M, Kragsbjerg P, Forsgren M, et al. Tumor necrosis factor-alpha (TNF alpha) in cerebrospinal fluid from patients with meningitis of different etiologies: high levels of TNF alpha indicate bacterial meningitis. I Infect Dis 1993;167:882-9.

43 Covelli V, Munno I, Pellegrino NM, et al. Exaggerated spontaneous release of tumor necrosis factor-alpha/ cachectin in patients with migraine without aura. Acta Neurol (Napoli) 1990;12:257-63.

44 Reus VI. Toward an understanding of cortisol dysregulation in major depression: a review of studies of the dexamethasone suppression test and urinary free-cortisol. Psychiatr Med 1985;3:1-21

45 Hoehn-Saric R, McLeod DR, Lee YB, et al. Cortisol levels in generalized anxiety disorder [letter]. Psychiatry Res 1991;38:313-5.

46 Hansen T, Bratlid T, Lingjarde O, et al. Midwinter insomnia in the subarctic region: evening levels of serum melatonin and cortisol before and after treatment with bright artificial light. Acta Psychiatr Scand 1987;75:428-34.

47 Riedel W, Layka H, Neeck G. Secretory pattern of GH, TSH, thyroid hormones, ACTH, cortisol, $\mathrm{FSH}$, and $\mathrm{LH}$ in patients with fibromyalgia syndrome following systemic injection of the relevant hypothalamic-releasing hormones. $Z$ Rheumatol 1998;57(suppl 2):81-7.

48 von Knorring L, Almay BG, Haggendal J, et al. Discrimination of idiopathic pain syndromes from neurogenic pain syndromes and healthy volunteers by means of clinical rating, personality traits, monoamine metabolites in CSF, ing, personality traits, monoamine metabolites in serum cortisol, platelet $\mathrm{MAO}$ and urinary

49 Plotsky PM, Owens MJ, Nemeroff CB. Psychoneuroendocrinology of depression. Hypothalamic-pituitary-adrenal axis. Psychiatr Clin North Am 1998;21:293-307.

50 Bodnar RJ, Kelly DD, Brutus M, et al. Stress-induced analgesia: neural and hormonal determinants. Neurosci Biobehav Rev 1980;4:87-100.

51 Vance ML, Kaiser DL, Frohman LA, et al. Role of dopamine in the regulation of growth hormone secretion: dopamine and bromocriptine augment growth hormone (GH)-releasing hormone-stimulated $\mathrm{GH}$ secretion in normal man. f Clin Endocrinol Metab 1987;64:1136-41. 